University of Konstanz

Department of Economics

\title{
Stop Watching and Start Listening! The Impact of Coaching and Peer Observation in Tournaments
}

Gerald Eisenkopf and Tim Friehe

Working Paper Series

2012-10

http://www.wiwi.uni-konstanz.de/forschung/ 


\title{
Stop Watching and Start Listening!
}

\section{The Impact of Coaching and Peer Observation in Tournaments}

\author{
Gerald Eisenkopf Tim Friehe $^{\#}$
}

June 27, 2012

\begin{abstract}
This paper uses experimental data to analyze how competitive behavior is influenced by coaching and peer observation. We study behavior in a sequential contest, considering information about the effort level of subjects in other contests (observation of peers) and information about the payoff-maximizing effort level (coaching) as treatment variables. Presentation of peer effort has a significant impact on the effort levels of first movers but not on second movers' effort levels. The decisions of second movers were positively influenced (in terms of payoffs) by coaching when this information was presented alone; however, when coaching was presented in combination with peer observation, the quality of second-mover decisions deteriorated.
\end{abstract}

Keywords: tournament; peer effect; coaching, information; learning

JEL-Codes: D03, D83, C90

\footnotetext{
* Thurgau Institute of Economics, Hauptstrasse 90, 8280 Kreuzlingen, Switzerland; University of Konstanz Department of Economics, 78457 Konstanz, Germany; gerald.eisenkopf@uni-konstanz.de.

\# University of Konstanz, Department of Economics, 78457 Konstanz, Germany; tim.friehe@uni-konstanz.de. CESifo, Munich, Germany.
} 


\section{Introduction}

\subsection{Motivation and Main Results}

The well-documented large variance in individual effort levels ${ }^{1}$ in experimental tournaments suggests that participants have difficulty identifying optimal effort. A complex choice can induce competitors to utilize additional information to assist their decision-making process. This information might be a recommendation from a coach or other authority, or it might derive from the example set by another person in a similar contest. In this paper, we present the results of an experiment that tested how additional information influences decisionmaking behavior.

More specifically, we consider two kinds of information sources that differ with respect to information quality. We examine seemingly reliable coaching information (i.e., information on the payoff-maximizing effort level) and relatively less reliable peer observation (i.e., information on the effort level of a subject in a similar contest). On the basis of this objective difference in information quality, one might hypothesize that subjects would rely more heavily on the advice of a coach and disregard peer observation when both coaching information and peer information are made available.

Our experiment employed a sequential two-player tournament with observable firstmover effort, thereby eliminating strategic uncertainty for second movers. This enabled us to isolate the impact and interaction of coaching and peer influence in a competitive environment.

This paper analyzes whether or not peer observation interferes with coaching. Peer information may distract decision makers from other relevant information (i.e., information about payoff-maximizing responses). Performance often declines when individuals try to

\footnotetext{
${ }^{1}$ See, for example, Bull et al. (1987), Harbring and Irlenbusch (2003), and Orrison et al. (2004).
} 
process multiple information sources. For instance, Hirshleifer et al. (2009) observe the repercussions of informational overload in financial markets; DellaVigna (2009) discusses the limits of attention more generally. Our second research question concerns whether or not first movers rely more on peer observation than second movers do. Studies have shown that people make decisions contingent on the observed choices of others in many non-competitive settings, in particular in situations that involve decisions made in uncertain circumstances (e.g., Cooper and Rege 2011). This observation can be explained by different motivations. For instance, social psychology provides extensive evidence for the importance of conformity; participants thus might seek to align their choices with those of others. However, many rationalizations of the correlation between individual actions refer to the possibility that the decisions of others may be used in an attempt to improve the quality of one's own decisionmaking. This motivation may arise because the actions of others incorporate information not accessible to the decision maker (e.g., Bikhchandani et al. 1998) or because very complex decision problems induce the individual to resort to the heuristic of imitation (Apesteguia et al. 2007). On this basis, first movers may be expected to rely more on peer observation than second movers, either because observational learning will play a role only for first movers, or because the decision problem of the first mover is more complex than that of second movers (as the second mover can decide without strategic uncertainty).

Our analysis shows that the decision makers who faced a complex decision problem (i.e., the first movers) relied to some extent on information about peer effort, while this effect was insignificant for second movers. There was a significant coaching effect among second movers; however, the joint presentation of coaching information and peer observation impeded the positive effects of coaching. Taken together, these findings do not support the importance of either conformity or imitation in the given setting; rather, they are consistent with observational learning by first movers. 


\subsection{Relation to the Literature}

There are several contributions to the literature that analyze the complexity of tournament decision-making in contexts in which strategically relevant information is provided, such as feedback about one's success in a dynamic setting or information on the characteristics of one's competitors (see, inter alia, Datta Mago et al. 2012, Eriksson et al. 2009, Kuhnen and Tymula 2012, Ludwig and Lünser 2008). In contrast, our paper provides evidence regarding the impact of information that does not similarly influence the strategic situation because our second movers know about the behavior of their competitor in all experimental treatments. ${ }^{2}$

The large variation in the choice of effort level referred to above may be explained by the various preferences that can affect competitive behavior. For example, some studies suggest that loss aversion shapes competitive behavior (Gill and Stone 2010, Gill and Prowse 2012). Differences in envy or compassion also provide an explanation for effort level variance (Grund and Sliwka 2005). Since we do not look at specific preferences, our contribution is complementary to this literature.

Our study is also related to the literature on observational learning (e.g., Cai et al. 2009, Celen and Kariv 2004, 2005) and imitation (e.g., Offerman et al. 2002, Offerman and Schotter 2009). Our set-up differs from the standard model used in the investigation of observational learning, in that we provide information about the effort of only one other participant. However, this is typical of work or social contexts in which a colleague or an acquaintance provides peer information. Indeed, at times people make very important decisions with longlasting repercussions based on the recommendations of only a few other people. For example, van Rooij et al. (2011) document the importance of family and friends in financial decisionmaking. Moreover, with regard to peer observation, the participants in our experiment only obtained information about the level of peer effort, in contrast to models of imitation in which individuals observe both the action taken and the outcome achieved by this action. This makes

\footnotetext{
${ }^{2}$ Theoretical contributions on sequential contests include Leininger (1993) and Morgan (2003).
} 
pure imitation of peer effort less likely in our experiment. In contrast, the information second movers in our set-up receive regarding the payoff-maximizing effort level (i.e., the coaching information) is directly related to the payoff outcome, making imitation more likely.

In addition to observational learning and imitation, our contribution is also linked to the literature on peer effects more generally. In this regard, it is important to note that there is payoff-independence between the participants we consider to be peers; that is, our participants receive information about a peer's behavior in similar circumstances, but do not directly compete with these peers in terms of outcomes. This differs from the work of Eriksson et al. (2009), for example. In general, the evidence on the influence of peer effects is inconclusive, as it prompts higher effort in some settings but lower effort in others. For example, Bellmare et al. (2010) study the performance of participants who were paid for a data-entry task either under peer pressure (i.e., when given information about the productivity of other participants) or not; their results indicate that peer pressure lowers productivity. A contrary finding has been documented by Falk and Ichino (2006), who observe subjects stuffing envelopes for a fixed payment either alone or in pairs (able to see the other's output), finding that output is higher in the latter scenario.

The focus of the present study - the influence of the presentation of peer effort and coaching information in a sequential tournament between two contestants - touches upon the issues described above but is still distinct in important ways. To the best of our knowledge, this topic has not yet been addressed in the literature.

The rest of the paper is structured as follows: Section 2 describes the experimental design. Section 3 discusses behavioral hypotheses. The experimental data is analyzed in Section 4, and the study is concluded in Section 5. 


\section{Experimental design}

Subjects participated in a one-shot sequential tournament in groups of two. Subjects remained anonymous throughout the experiment, and the allocation of subjects into groups was random. All subjects received the same instructions. After reading the instructions and answering the control questions correctly, the roles of first and second mover were randomly assigned to group members. The experiment was conducted in German. A translated version of the instructions is provided in Appendix A.

First and second movers competed against each other for a prize of 280 points by choosing a (monetary) effort level $e$ between 0 and 15. Each subject had an endowment of 225 points to cover the costs of effort $\left(c(e)=e^{2}\right)$. Subjects kept the remaining endowment. After subjects selected an effort level, they were informed about the costs of effort and the possible payoffs involved. Subjects could then either revise their decision or confirm it. When determining their effort level, second movers knew the first-mover effort (i.e., the first mover's final effort choice was irreversible, and first-mover effort was perfectly observable for the second mover).

The effort levels determined who would obtain the prize using a so-called probit-form contest success function (e.g., Dixit 1987). The effort of each subject was distorted by a random variable $(\varepsilon)$ drawn independently for each subject from a uniform distribution between -7 and 7 . The instructions contained a table that informed the subjects about their probability of winning the prize given the various possible differences in effort levels between the two competitors. At the end of this one-shot game, the participant with the highest (distorted) effort won the prize.

Treatments differed with respect to the information presented on the screen before subjects made their decision. Participants were informed that the decision-making screen might include additional information, without specifying its nature. 
The first movers were divided into two treatment groups. In the peer treatment, first movers were informed about the behavior of another first mover. In the no information treatment, the first movers did not receive any information about the behavior of other participants.

For the second movers, we implemented a $2 \times 2$ design. By the nature of our sequential tournament, all second movers were aware of first-mover effort. We informed some second movers about the effort level of another second mover (the peer) who had responded to the same first-mover effort. In addition to this variation with regard to whether or not subjects were informed about peer effort, we also provided some participants with coaching information about the effort level that would maximize their expected monetary payoffs (i.e., the best response). We therefore obtained the following four treatments for the second movers:

Table 1: Classification of second-mover treatments.

Information about

\section{Peer effort}

Yes No

Best Response

Yes full information $(\mathrm{B} \& \mathrm{P}) \quad$ best response $(\mathrm{B})$

No $\quad$ peer $(\mathrm{P}) \quad$ no information $(\mathrm{N})$ 
In order to ensure similarity of the peer effects presented in the peer and the full information treatments, we informed participants in these treatments about the behavior of a randomly chosen participant who had acted as a second mover in our best response treatment. The computer screen stated that the peer information came from a second mover in a previous session who had reacted to the same first-mover effort. Our analysis of second-mover effort levels controls for first-mover effort levels and the corresponding best responses.

Table 2 summarizes the design of the experiment.

Table 2: Design of the experiment.

\begin{tabular}{lc} 
Instructions & Identical for all participants (see Appendix A) \\
\hline Step 1: & Random assignment of roles (first mover or second mover) \\
\hline Step 2: & \multicolumn{2}{c}{ Treatment differentiation (first movers) } \\
& $\begin{array}{l}\text { peer } \\
\text { Receives information about the } \\
\text { behavior of another first mover }\end{array}$
\end{tabular}

First mover makes effort choice

Step 3 Second mover learns about the behavior of the first mover

Treatment differentiation (second movers)

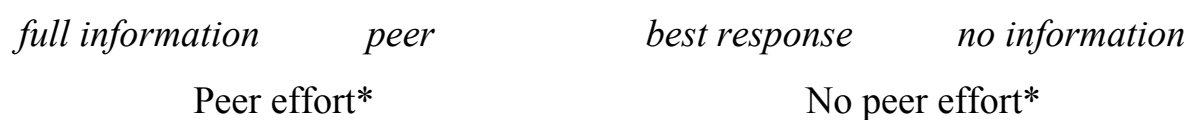

$\begin{array}{llll}\begin{array}{l}\text { Best } \\ \text { response }^{+}\end{array} & \begin{array}{l}\text { No best } \\ \text { response }\end{array} & \text { Best response }^{+} & \begin{array}{l}\text { No best } \\ \text { response }\end{array}\end{array}$

Second mover makes effort choice

Step 4

Information about actual pay-offs

* Peer effort: Second mover receives information about the behavior of another second mover who faced the same first-mover effort.

${ }^{+}$Best response: Second mover receives information about the response that would maximize expected payoffs.

All behavioral information derived from treatment B.

The experiment was computerized using "z-Tree" software (Fischbacher 2007); recruitment was conducted using "ORSEE" (Greiner 2003). All sessions took place in the lakelab at the University of Konstanz, with students from this university as the participants. 
324 subjects took part in the experiment in sessions lasting about 45 minutes. On average, subjects earned $€ 14.27$ for their participation

\section{Behavioral Predictions}

In the following subsections, we will elaborate on the possible ways in which the provision of information in our experiment could influence decision-making and final outcomes. First, in Section 3.1, we describe the equilibrium that standard theory would predict. In this scenario, the different treatments we employ would all lead to the same equilibrium. In Section 3.2, we consider the possible effects resulting from participant observation of peer effort. Coaching is addressed in Section 3.3.

\subsection{Rational subjects with standard preferences}

Assume that contestants are risk-neutral actors who seek to maximize expected monetary payoffs (e.g., Dixit 1987). The expected monetary payoffs are characterized by the level of the endowment, the contest prize, the probability of winning the contest prize, and effort costs. All of these aspects are the same for all participants. With common knowledge of rationality, preferences, and payoffs, subjects can construct the objective function of their opponent without need for additional information.

For the game specified in Section 2, the expected payoffs for contestant $i$ are given by

$$
\prod_{i}=225+p_{i}\left(e_{F}, e_{S}\right) 280-e_{i}^{2},
$$

where $i=F, S$ denotes either the first or the second mover, and $p_{i}$ denotes contestant $i$ 's probability of winning the contest.

We use backward induction to solve the game, considering that the first mover will anticipate how the second mover will respond to a given level of first-mover effort. The bestresponse function of the second mover is piece-wise linear and can be represented by 
$e_{S}=\left\{\begin{array}{l}1 / 12\left[70+5 e_{F}\right] \text { for } e_{F} \leq 10 \\ 1 / 2\left[70-5 e_{F}\right] \text { for } e_{F}>10\end{array}\right.$

The Nash equilibrium of the sequential tournament is given by a first-mover effort of about 12.6 and a second-mover effort of about 3.6. Accordingly, the first (second) mover will invest more (less) in a sequential tournament than in a simultaneous-move tournament (in which equilibrium efforts are equal to ten). Under these conditions, information regarding the best response and/or the behavior of a peer in an unrelated game should not affect participants' decisions. Therefore, we obtain the following hypothesis:

H0: We do not observe behavioral differences across treatments. This holds for both first and second movers.

This hypothesis represents the benchmark for the assessment of the various treatments. Next, we sketch briefly what we consider to be the most plausible alternative hypotheses to H0. Since we do not test for specific behavioral mechanisms of information provisions, it is beyond the scope of this paper to formally derive the alternative hypotheses. 


\subsection{Impact of peer information}

Although our design ensures that subjects are symmetric with respect to prizes and effort costs, it is likely that substantial heterogeneity remains and that this is indeed anticipated by our participants. Differences in cognitive capabilities and preferences are the key causes of this heterogeneity. In this scenario, additional information about the decision of an unrelated peer could affect the choices of competitors. This holds in particular for first movers who know basically nothing about their respective second movers. The peer effort provides information about what another person considered to be the optimal choice. Hence, observational learning (as well as imitation, anchoring, or a preference for conformity) would suggest that first movers will align their effort choice with the displayed choice of a peer first mover. Competitive or envious people (e.g., as in Grund \& Sliwka 2005) may also adjust their effort choice according to the behavior of their peers because this provides information about the competitiveness of the population of participants. Even though there are plausible arguments for a negative correlation between effort choice and peer information, Hypothesis $\mathrm{H} 1$ (below) is clearly the most plausible alternative for $\mathrm{H} 0$ with respect to first movers.

The motivations related to imitation, anchoring, or a preference for conformity similarly apply to second movers. However, the second mover is aware of first-mover effort and thus need not rely on peer effort to distill information relevant to the strategic interaction. This difference in the significance of the observation learning potential of peer effort leads us to expect that the quantitative effect of peer effort will differ markedly between first and second movers.

H1: First-mover effort is increasing in peer effort. Second mover effort is independent of peer effort. 


\subsection{Impact of best-response information on second movers}

Once we acknowledge that many second movers find it difficult to choose effort, the effect of providing coaching information about the payoff-maximizing effort level suggests a very plausible alternative to H0. Given that it conveys payoff-maximizing information, this coaching is associated with a high information quality, which would lead us to expect that subjects in the best response treatment will follow the coaching recommendation. In the treatment full information, subjects are informed about both the best response and peer effort. However, given that we hypothesize in $\mathrm{H} 1$ that peer information will be irrelevant for second movers, we do not expect that the additional display of peer information will modify the impact of the best response.

H2: The level of the best response is a stronger predictor of second-mover effort in treatments full information and best response than in the other treatments.

Note that $\mathrm{H} 2$ allows for a role of the best response in the other treatments, because second movers may themselves figure out the effort level that corresponds with the best response. However, the actual presentation of the best response in treatments best response and full information leads us to expect a closer alignment of the best response and the effort levels actually chosen by our participants in these treatments.

\section{Results}

Table 3 shows the descriptive statistics regarding the effort choice of first and second movers in our various treatments. The table indicates both the effort choice and the underlying costs. We focus our analysis on the effort level because we consider it to be the more transparent parameter. In any case, all subsequent results are robust for both effort choice and the associated costs. 
First movers who observe peer effort do not provide significantly lower effort than first movers without additional information. The p-values for treatment differences in effort choice and costs are $\mathrm{p}=.307$ and $\mathrm{p}=.155$, respectively. We also observe no significant treatment differences for second movers. With respect to second movers, the lowest p-value is found in the difference in cost of effort between the no information and best response treatments $(\mathrm{p}=.101)$.

Table 3: Average effort levels and costs for first and second movers across treatments (standard deviations in parentheses).

First Mover

\begin{tabular}{|c|c|c|c|c|}
\hline \multirow{3}{*}{ Effort } & \multicolumn{2}{|l|}{ peer } & \multicolumn{2}{|c|}{ no information } \\
\hline & \multicolumn{2}{|l|}{7.780} & \multicolumn{2}{|c|}{8.138} \\
\hline & \multicolumn{2}{|c|}{$(4.214)$} & \multicolumn{2}{|c|}{$(4.781)$} \\
\hline \multirow[t]{2}{*}{ Cost of Effort } & \multicolumn{2}{|c|}{78.073} & \multicolumn{2}{|c|}{88.788} \\
\hline & \multicolumn{2}{|c|}{$(60.523)$} & \multicolumn{2}{|c|}{$(72.981)$} \\
\hline \multirow[t]{3}{*}{$\mathrm{N}$} & \multicolumn{2}{|l|}{82} & \multicolumn{2}{|c|}{80} \\
\hline & \multicolumn{4}{|c|}{ Second Mover } \\
\hline & $\begin{array}{l}\text { full information } \\
\qquad(\mathrm{B} \& \mathrm{P})\end{array}$ & $\begin{array}{c}\text { peer } \\
(\mathrm{P})\end{array}$ & $\begin{array}{l}\text { best response } \\
\text { (B) }\end{array}$ & $\begin{array}{l}\text { no information } \\
(\mathrm{N})\end{array}$ \\
\hline \multirow[t]{2}{*}{ Effort } & 8.404 & 8.543 & 7.870 & 8.559 \\
\hline & $(3.745)$ & $(4.481)$ & (4.009) & (5.064) \\
\hline \multirow[t]{2}{*}{ Cost of Effort } & 84.361 & 92.486 & 77.653 & 98.147 \\
\hline & $(59.145)$ & $(68.582)$ & $(60.825)$ & $(82.073)$ \\
\hline $\mathrm{N}$ & 47 & 35 & 46 & 34 \\
\hline
\end{tabular}

As a first step in our analysis, we consider whether or not first-mover effort indicates a response in any way to the level of peer effort presented. We find a significant effect for first movers in the peer treatment (see Table 4). When peer effort increased by one point, first 
movers increased their effort by about 0.184 points. Thus, peers provide a limited benchmark for behavior when there is no precise information about the behavior of the competitor.

Table 4: Impact of peer effort on first-mover effort in the peer treatment (OLS estimation).

\begin{tabular}{lc}
$\begin{array}{l}\text { dependent } \\
\text { variable }\end{array}$ & first-mover effort \\
\hline Peer effort & $0.184 *(0.106)$ \\
Constant & $6.333^{* * *}(1.074)$ \\
$\mathrm{N}$ & .0434 \\
$\mathrm{R}^{2}$ & 82 \\
\hline $\begin{array}{l}\text { The table displays coefficients with robust standard errors in } \\
\text { parentheses. } * \text { significant at } \mathrm{p}<.1 ; * * \text { significant at } \mathrm{p}<.05 ;\end{array}$ \\
$* * *$ significant at $\mathrm{p}<.01$
\end{tabular}

We now focus our analysis on the effort choice of the second mover. Given the higher number of treatments, there are naturally more facets to this exploration.

To continue the analysis of peer observation and in order to address the second part of Hypothesis H1, we first focus on the influence of peer effort on second movers. Table 5 shows the impact of peer effort on the effort choices of second movers in the full information and peer treatments. Models $1 \mathrm{a}$ and $1 \mathrm{~b}$ provide a very simple estimation. Models $2 \mathrm{a}$ and $2 \mathrm{~b}$ control for the best response, and Models $3 \mathrm{a}$ and $3 \mathrm{~b}$ distinguish between high and low firstmover effort (where first mover high=1 indicates that first-mover effort was ten or higher). The distinction between high and low first-mover effort is important because the bestresponse function has a kink at $e_{F}=10$, changing the sign of its slope (see equation (2)). In contrast to the finding for first movers, we do not find a peer effect for second movers. ${ }^{3}$ The only meaningful significant effect occurred in the full information treatment in Model 3a, where we observe that peer effort depresses second-mover effort when first-mover effort is

\footnotetext{
${ }^{3}$ We also tested regressions, taking the difference between the best response and the peer information into account, without any change in the result.
} 
high. This result points to a payoff-deteriorating aspect of peer information, because the peer effort was on average rather informative regarding the payoff-maximizing behavior. The responsiveness of first movers regarding peer-effort levels and the lack of interdependence between second-mover effort and peer effort confirm Hypothesis H1.

Table 5: Impact of peer effort on second-mover effort choice (OLS estimations).

\begin{tabular}{|c|c|c|c|c|c|c|}
\hline Treatment & \multicolumn{3}{|c|}{ full information } & \multicolumn{3}{|c|}{ peer } \\
\hline \multirow[t]{3}{*}{$\mathrm{N}$} & \multicolumn{3}{|c|}{47} & \multicolumn{3}{|c|}{35} \\
\hline & Model & Model & Model & Model & Model & Model \\
\hline & $1 \mathrm{a}$ & $2 a$ & $3 a$ & $1 b$ & $2 b$ & $3 b$ \\
\hline Door offort & -0.075 & -0.079 & 0.012 & 0.117 & 0.146 & 0.109 \\
\hline & $(0.139)$ & $(0.141)$ & $(0.170)$ & $(0.168)$ & $(1.050)$ & $(0.224)$ \\
\hline First mover hioh & & & 7.289 & & & 3.420 \\
\hline & & & (6.614) & & & $(5.262)$ \\
\hline (First mover high) & & & $-0.672 *$ & & & 0.133 \\
\hline$\times$ Peer effort & & & $(0.396)$ & & & $(0.408)$ \\
\hline Doct manong & & 0.371 & 0.597 & & -0.099 & 0.273 \\
\hline 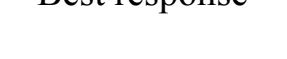 & & $(0.332)$ & $(0.511)$ & & $(0.232)$ & $(0.487)$ \\
\hline (First mover high) & & & -0.106 & & & -0.380 \\
\hline$\times$ Best response & & & $(0.710)$ & & & $(0.696)$ \\
\hline Congtont & $8.937 * * *$ & $6.135^{*}$ & 3.773 & $7.878 * * *$ & $8.319 * * *$ & 5.009 \\
\hline & $(1.082)$ & $(3.065)$ & (4.618) & $(1.312)$ & $(2.159)$ & $(4.720)$ \\
\hline $\mathrm{R}^{2}$ & .008 & .039 & .111 & .019 & .024 & .048 \\
\hline
\end{tabular}

The table displays coefficients with robust standard errors in parentheses.

$*$ significant at $\mathrm{p}<.1 ; * *$ significant at $\mathrm{p}<.05 ; * * *$ significant at $\mathrm{p}<.01$ 
As the next step in our analysis, we turn to the relationship between second-mover effort and the presentation of coaching information, controlling for the presence of peer information. Tables 6-8 will address these issues using different estimations with increasing sophistication. Table 6 reports the findings from estimating second-mover effort as a function of the best response. Due to collinearity, we do not include first-mover effort as an explanatory variable in our estimation. ${ }^{4}$ Second movers in both the full information and the best response treatment received information about the best possible response before they made their final decision. The estimation shows that the best response is a significant predictor only in the best response treatment, but not in the full information treatment. When comparing the peer effort and no information treatments, we find that the presentation of peer effort does not result in a systematic relationship between second-mover effort and the best response. In this regard, peer information has no beneficial effect.

Table 6: Impact of best response on second-mover effort (OLS estimations).

\begin{tabular}{ccccc} 
Treatment & B\&P & $\mathrm{P}$ & $\mathrm{B}$ & $\mathrm{N}$ \\
$\mathrm{N}$ & 47 & 35 & 46 & 34 \\
\hline \multirow{2}{*}{ Level of best response } & .365 & .0132 & $.744^{* * *}$ & .328 \\
& $(.332)$ & $(.256)$ & $(.144)$ & $(.273)$ \\
Constant & 5.616 & $8.457^{* * *}$ & $2.709^{* *}$ & $6.642^{* * *}$ \\
$\mathrm{R}^{2}$ & $(2.709)$ & $(2.099)$ & $(1.160)$ & $(2.118)$ \\
& .030 & .000 & .327 & .058 \\
\hline
\end{tabular}

Displayed are coefficients with robust standard errors in parentheses. ${ }^{*}$ significant at $\mathrm{p}<.1 ; * *$ significant at $\mathrm{p}<.05 ; * * *$ significant at $\mathrm{p}<.01$

In reference to Hypothesis $\mathrm{H} 2$, we can confirm that the level of the best response is an important predictor of second-mover effort in the best response treatment, but we cannot confirm that the level of the best response predicts second-mover effort in the full information treatment. It would seem that the provision of peer effort information distracts second movers

\footnotetext{
${ }^{4}$ Appendix B documents estimation results with first-mover effort as an explanatory variable.
} 
from effectively utilizing the coaching information. In other words, the peer observation adversely interferes with coaching.

We now discuss the detrimental effect of peer information on the relationship between best-response effort and second-mover effort in greater detail. Table 7 reports findings from an econometric model that includes the additional dummy variable (i.e., a first-mover effort level above 10). The model also examines the interaction between this dummy and the best response. This interaction reveals to what extent second movers consider the best response at high first-mover effort levels $(\geq 10)$.

Table 7: Impact of best response on second-mover effort (OLS estimations).

\begin{tabular}{c|cccc} 
Treatment & B\&P & $\mathrm{P}$ & $\mathrm{B}$ & $\mathrm{N}$ \\
\hline $\mathrm{N}$ & 47 & 35 & 46 & 34 \\
\hline \multirow{2}{*}{ Level of best response } & 0.598 & 0.166 & $1.088^{* *}$ & $1.386^{* * *}$ \\
& $(0.501)$ & $(0.432)$ & $(0.521)$ & $(0.484)$ \\
First mover high & 3.268 & 1.834 & 3.306 & $8.748^{*}$ \\
First mover high $\times$ & $(5.707)$ & $(4.230)$ & $(4.542)$ & $(4.847)$ \\
Level of best response & -0.462 & -0.003 & -0.366 & $-1.189^{*}$ \\
& $(0.735)$ & $(0.556)$ & $(0.547)$ & $(0.591)$ \\
Constant & 3.836 & $6.628^{*}$ & -0.141 & -1.737 \\
\hline $\mathrm{R}^{2}$ & $(4.303)$ & $(3.577)$ & 4.390 & $(4.291)$ \\
\hline
\end{tabular}

The table displays coefficients with robust standard errors in parentheses.

$*$ significant at $\mathrm{p}<.1 ; * *$ significant at $\mathrm{p}<.05 ; * * *$ significant at $\mathrm{p}<.01$

The results show that average effort in the best response treatment reflects the best response accurately, i.e., coaching in isolation is effective. Surprisingly, we find a similar result for the no information treatment. However, for high levels of first-mover effort, the best response does not explain decisions in the no information treatment, while the effect is still significant in the best response treatment. Table B1 in the appendix documents the 
explanation. Best-response information induces subjects to respond with particularly low effort to increasing first-mover effort, thus deterring second movers from costly retaliations against highly competitive first movers. The results from Table 7 suggest that peer information (in the full information and peer effect treatments) neutralizes any meaningful significant effect of the best response. Peer information seems to induce effort choices that reduce expected payoffs.

This curious finding is taken up in Table 8. We compare the influence of the best response across treatments (with no information as the baseline and peer and best response treatments and their interaction as dummy variables), documenting separate estimations for high and low first-mover effort levels. Average second-mover effort follows the best response quite closely when first-mover effort is low. The presentation of peer information eliminates this dependence (see interaction $\mathrm{P} \times$ Level of best response). When first-mover effort is low, second movers do not require coaching in order to arrive at decisions that correspond with the best-response effort level. When first-mover effort is high, the effect of best-response information on second-mover effort is not significant. These results stand in contrast to Hypothesis $\mathrm{H} 2$, in which we hypothesized that best-response effects would be relevant in treatments best response and full information, but less so in no information. 
Table 8: Treatment differences in the impact of best responses on second-mover effort (OLS estimations; baseline treatment: no information).

\begin{tabular}{|c|c|c|}
\hline Treatment & First-mover effort $<10$ & First-mover effort $\geq 10$ \\
\hline $\mathrm{N}$ & 92 & 70 \\
\hline Level of best response & $1.386 * * *(0.476)$ & $0.197(0.338)$ \\
\hline Treatment $\mathrm{P}$ & $8.365(5.496)$ & $1.451(3.188)$ \\
\hline $\mathrm{P} \times$ Level of best response & $-1.220 *(0.638)$ & $-0.034(0.487)$ \\
\hline Treatment B & $1.596(6.088)$ & $-3.846(2.543)$ \\
\hline $\mathrm{B} \times$ Level of best response & $-0.298(0.705)$ & $0.525(0.378)$ \\
\hline Treatment $\mathrm{B} \& \mathrm{P}(=\mathrm{P} \times \mathrm{B})$ & $-4.388(8.248)$ & $2.488(5.107)$ \\
\hline $\mathrm{P} \times \mathrm{B} \times$ Level of best response & $0.730(0.964)$ & $-0.551(0.751)$ \\
\hline Constant & $-1.736(4.219)$ & $7.011 * * *(2.250)$ \\
\hline $\mathrm{R}^{2}$ & .138 & .127 \\
\hline
\end{tabular}

The table displays coefficients with robust standard errors in parentheses.

$*$ significant at $\mathrm{p}<.1 ; * *$ significant at $\mathrm{p}<.05 ; * * *$ significant at $\mathrm{p}<.01$

The results suggest that the peer information distracts decision makers from maximizing their payoffs, even though we observe no tendency towards conformity or imitation among second movers.

\section{Conclusion}

People use the behavior of others in many ways and for different reasons when determining their own actions. This paper reports the findings of an economic experiment in which participants competing in a sequential tournament were presented with information about the effort invested by another subject in a similar situation. We find that first movers rely in a predictable way on peer effort; in contrast, second-mover effort is not a function of peer effort. This difference in the impact of peer information may be interpreted as indicating observational learning. 
We identify the relevance of peer information for second movers by an additional treatment variation. Some second movers were coached regarding the level of the best response. The analysis establishes that second movers without peer information indeed closely tied their effort choice to the coaching information. However, the second-mover effort of subjects who received peer information in addition to the coaching showed no dependence on the payoff-maximizing response. This indicates confusion among the second movers who received two signals. Peer information, when it affected second movers, resulted in a reduction in the expected payoffs by limiting the effect of the more reliable coaching information

The present study highlights the fact that providing decision makers with information may lead to both sensible uses and misuse. As a result, policy makers must be wary regarding their information policy, because the quality of decentralized decision-making is not necessarily best served by providing more information. Overall, the results suggest that the selective presentation of information (i.e., the possible suppression of some information) might positively influence participants' welfare. More specifically, in contexts with multiple contests (i.e., in corporate settings or major sporting events), it could be more effective to restrict information about participants in parallel contests in order to avoid negative effects.

\section{Acknowledgments}

We thank Urs Fischbacher, Kate Bendrick, Lisa Bruttel, Simeon Schudy, Verena Utikal, Irenaeus Wolff, and seminar participants at the Thurgau Experimental Economics Meeting for their contribution and support. The usual disclaimer applies. 


\section{Bibliography}

Apesteguia, J., Huck, S., and J. Oechssler, 2007. Imitation - Theory and experimental evidence. Journal of Economic Theory 136, 217-235.

Bellemare, C., Lepage, P., and B. Shearer, 2010. Peer pressure, incentives, and gender: An experimental analysis of motivation in the workplace. Labour Economics 17, 276-283.

Bikhchandani S., Hirshleifer, D., and I. Welch, 1998. Learning from the behavior of others: Conformity, fads, and informational cascades. Journal of Economic Perspectives 2, 151-170.

Bull, C., Schotter, A., and K. Weigelt, 1987. Tournaments and piece rates: An experimental study. Journal of Political Economy 95, 1-33.

Cai, H., Chen, Y., and H. Fang, 2009. Observational learning: Evidence from a randomized natural field experiment. American Economic Review 99, 864-882.

Celen, B., and S. Kariv, 2004. Distinguishing informational cascades from herd behavior in the laboratory. American Economic Review 94, 484-498.

Celen, B., and S. Kariv, 2005. An experimental test of observational learning under imperfect information. Economic Theory 26, 677-699.

Cooper, D.J., and M. Rege, 2011. Misery loves company: Social regret and social interaction effects in choices under risk and uncertainty. Games and Economic Behavior 73, 91110.

Datta Mago, S., Savikhin, A., and R.M. Sheremeta, 2012. Facing your opponents: Social identification and information feedback in contests. Working Paper Chapman University, Economic Science Institute.

DellaVigna, S., 2009. Psychology and economics: Evidence from the field. Journal of Economic Literature 47, 315-372.

Dixit, A., 1987. Strategic behavior in contests. American Economic Review 77, 891-898. 
Eriksson, T., Poulsen, A., and M.C. Villeval, 2009. Feedback and incentives: Experimental evidence. Labour Economics 16, 679-688.

Falk, A., and A. Ichino, 2006. Clean evidence on peer effects. Journal of Labor Economics 24, 39-57.

Fischbacher, U., 2007. Z-Tree: Zürich Toolbox for Ready-Made Economic Experiments. Experimental Economics 10, 171-178.

Gill, D., and V. Prowse, 2012. A structural analysis of disappointment aversion in a real effort competition. American Economic Review 102, 469-503.

Gill, D., and R. Stone, 2010. Fairness and desert in tournaments. Games and Economic Behavior 69, 346-364.

Greiner, B., 2003. An online recruitment system for economic experiments. In: Kremer, K., and V. Macho Eds., Forschung und wissenschaftliches Rechnen, GWDG Bericht 63, Göttingen: Ges. für Wiss. Datenverarbeitung, 79-93.

Grund, C., and D. Sliwka, 2005. Envy and compassion in tournaments. Journal of Economics \& Management Strategy 14, 187-207.

Harbring, C., and B. Irlenbusch, 2003. An experimental study on tournament design. Labour Economics 10, 443-464.

Hirshleifer, D., Lim, S.S., and S.H. Teoh, 2009. Driven to distraction: Extraneous events and underreaction to earnings news. Journal of Finance 64, 2289-2325.

Kuhnen, C.M., and A. Tymula, 2012. Feedback, self-esteem and performance in organizations. Management Science 58, 94-113

Leininger, W., 1993. More efficient rent-seeking - A Münchhausen solution. Public Choice $75,433-462$.

Ludwig, S., and G. Lünser, 2008. Knowing the gap - Intermediate information in tournaments. ELSE Working Papers (312). ESRC Centre for Economic Learning and Social Evolution, London, UK. 
Morgan, J., 2003. Sequential contests. Public Choice 116, 1-18.

Offerman, T., Potters, J., and J. Sonnemans, 2002. Imitation and belief learning in an oligopoly experiment. Review of Economic studies 69, 973-997.

Offerman, T., and A. Schotter, 2009. Imitation and luck: An experimental study on social sampling. Games and Economic Behavior 65, 461-502.

Orrison, A., Schotter, A., and K. Weigelt, 2004. Multiperson tournaments: An experimental examination. Management Science 50, 268-279.

Van Rooij, M., Lusardi, A., and R. Alessie, 2011. Financial literacy and stock market participation. Journal of Financial Economics 101, 449-472. 


\section{Appendix}

\section{Appendix A-Instructions}

We welcome you to this economic experiment.

Your decisions and possibly the decisions of other participants will influence your payment in this experiment. It is therefore very important that you read these instructions very carefully. If you have questions, please address them to us before the experiment begins. All participants will receive the same instructions.

During the experiment, talking to other participants is not allowed. Failure to comply with this rule will lead to exclusion from the experiment and forfeiture of payments.

In the experiment, we refer to points rather than euros. Your total income will initially be calculated in points. The total points earned in the experiment will be converted to euros at the end, with an exchange rate of

\section{5 points $=1$ euro}

Your payment will be made in cash at the end of today's experiment. In the following pages, we will explain the exact sequence of events for the experiment.

\section{Structure of the experiment}

In this experiment, a sum of 280 points will be allotted to you or another participant. This other participant will be randomly assigned to you and will remain anonymous throughout the entire experiment. Your anonymity will also be preserved. The other participant will receive the same instructions as you.

The allocation of the 280 points will depend on the input selected by you and by the other participant.

- If you increase your input, the probability that you will receive the sum goes up.

- If the other participant increases his or her input, your probability of receiving the sum will go down.

The minimum level for the input is 0 ; the maximum input is 15 . It is important to consider that a higher input is more costly. For your input choice, an endowment of 225 points is available to you. The points that you do not use for your input will be part of your payment at the end of the experiment. The following table shows the costs of each chosen input level.

\begin{tabular}{|l|l|l|l|l|l|l|l|l|l|l|l|l|l|l|l|l|}
\hline Input & 0 & 1 & 2 & 3 & 4 & 5 & 6 & 7 & 8 & 9 & 10 & 11 & 12 & 13 & 14 & 15 \\
\hline $\begin{array}{l}\text { Total cost } \\
\text { of input }\end{array}$ & 0 & 1 & 4 & 9 & 16 & 25 & 36 & 49 & 64 & 81 & 100 & 121 & 144 & 169 & 196 & 225 \\
\hline
\end{tabular}

As already mentioned, the probability that the sum will be allotted to you depends on your input as well as the input of the other participant. The following table represents the level of this probability. First, the difference between your input and the other participant's input is shown. Next to this, you will find the probability that you will receive the sum and the corresponding probability that the other participant will receive the sum. The computer decides the actual allotment of the sum. 
Table

Differences in input between the participants and the resulting probabilities of receiving the 280 points (rounded)

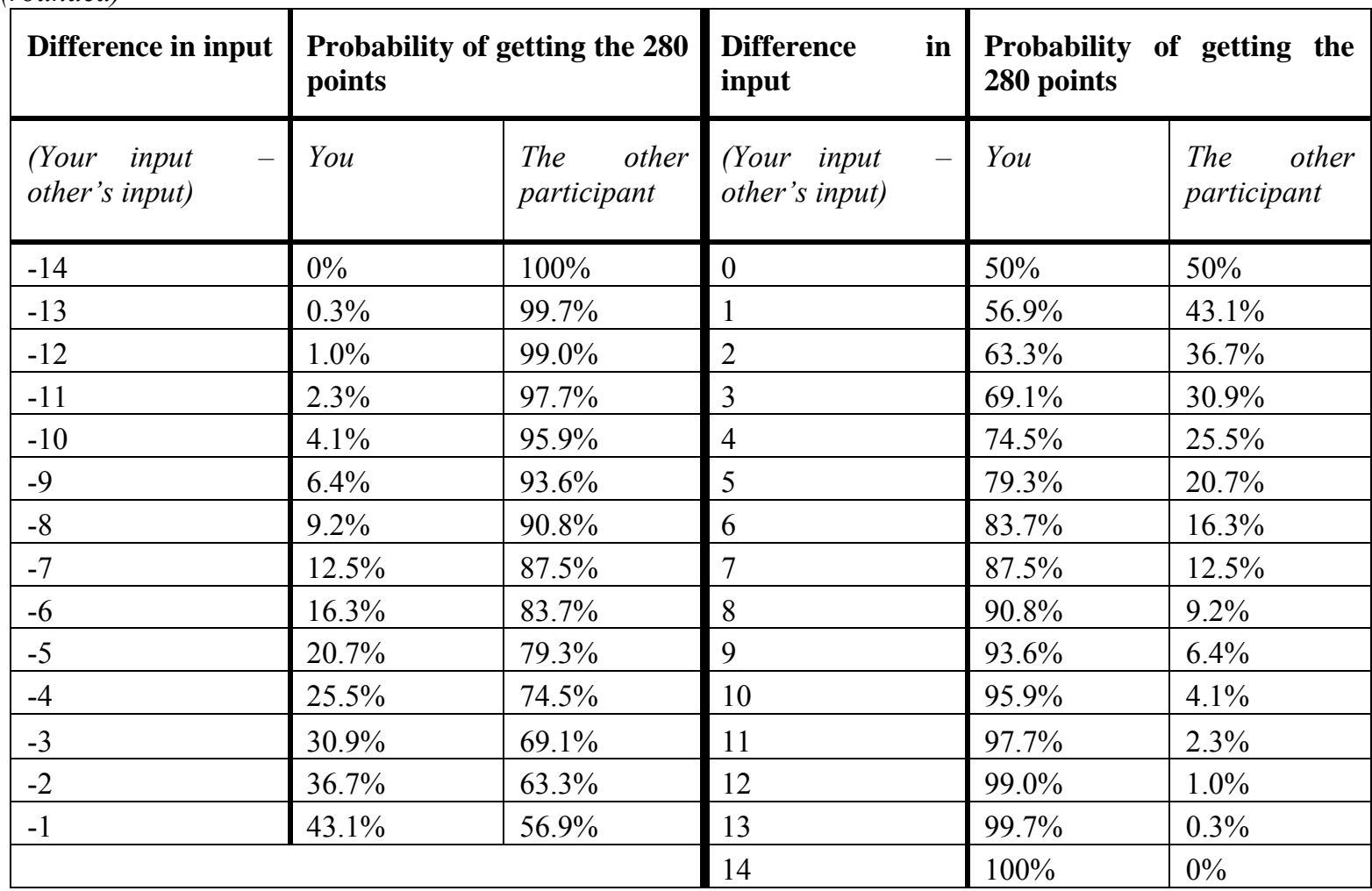

\section{Sequence of decisions}

The decisions on the level of input to obtain the 280 points are made one after the other. Whether you or the other participant will decide first is determined by a dice throw at the beginning of the experiment. The participant who decides first does not know the choice of the participant deciding second. The subject who decides second will be informed about the input level of the other party.

Both participants may receive additional information presented on the computer screen that may be of use in arriving at a decision.

\section{It is therefore important to carefully read through the information presented on the screen.}

You can enter your input level in a cell on the screen. You will then receive the opportunity to revise or confirm your first choice. When all participants have decided on their input levels, you will be informed of whether or not you have received the 280 points. The experiment continues with a questionnaire and concludes with payments to subjects.

\section{Example:}

You have to choose input first and select 12. The other participant chooses an input of 6 . The difference between your input and the other participant's input is thus $6(=12-6)$.

You will receive the 280 points with probability $83.7 \%$. Correspondingly, the other participant will receive the 280 points with a probability of $16.3 \%$. You and the other participant bear the input costs. An input level of 12 entails a cost of 144 points; an input level of 6 implies a cost of 36 points.

If the sum goes to you, your total payment will be 361 points (probability $83.7 \%$ ), and if the sum goes to the other participant you will be paid 81 points (probability $16.3 \%$ ). If you receive the sum, the other participant will receive 189 points (probability 83.7\%); otherwise, the other participant will receive 469 points (probability $16.3 \%$ ). The following table once again shows you a detailed calculation of the possible payments to you. 


\begin{tabular}{l|l|l|l|l} 
& \multicolumn{2}{|l|}{$\begin{array}{l}\text { Payment to you } \\
\text { Sum to you }\end{array}$} & $\begin{array}{l}\text { Sum to the other } \\
\text { participant }\end{array}$ & \multicolumn{2}{l}{$\begin{array}{l}\text { Payment to the other participant } \\
\text { Sum you }\end{array}$} & $\begin{array}{l}\text { Sum to the other } \\
\text { participant }\end{array}$ \\
\hline Probability & $83.7 \%$ & $16.3 \%$ & $83.7 \%$ & $16.3 \%$ \\
\hline Initial point level & 225 & 225 & 225 & 225 \\
\hline $\begin{array}{l}\text { Subtraction of the } \\
\text { cost of input }\end{array}$ & -144 & -144 & -36 & -36 \\
\hline Assignment & 280 & 0 & 0 & 280 \\
\hline Sum & 361 & 81 & 189 & 469
\end{tabular}

\section{Comprehension Questions}

Please mark the correct answer

\begin{tabular}{|l|l|l|}
\hline & True & False \\
\hline My payment depends on my input only. & & \\
\hline $\begin{array}{l}\text { I will receive the } 280 \text { points whenever my input exceeds that of the } \\
\text { other participant. }\end{array}$ & & \\
\hline $\begin{array}{l}\text { The participant who decides first has selected an input of 3. The } \\
\text { other participant will not be informed about this. }\end{array}$ & & \\
\hline
\end{tabular}

Question 1: You provide an input of 5, the other participant an input of 12.

- How high are your input costs; how high are the other participant's costs?

- How high is your probability of receiving the additional 280 points?

Question 2: You provide an input of 0 , the other participant an input of 15.

- What is the likelihood of you receiving the 280 points?

- How high is your payment at the end of the experiment? (in points)

- How high is the other participant's payment at the end of the experiment? (in points)

Question 3: You provide an input of 14, the other participant an input of 13.

- What is the likelihood of you receiving the 280 points?

- How high is your payment at the end of the experiment if you receive the sum? (in points)

- How high is your payment at the end of the experiment if the other participant receives the sum? (in points)

- How high is the payment to the other participant at the end of the experiment if you receive the sum? (in points)

- How high is the payment to the other participant at the end of the experiment if the other participant receives the sum? (in points) 
Appendix B - Estimations with first-mover effort as control variable

Table B1: The impact of first-mover effort on second-mover effort in the different treatments (OLS estimations).

\begin{tabular}{c|cc|cc} 
Treatment & full information & peer & best response & no information \\
\hline $\mathrm{N}$ & 47 & 35 & 46 & 34 \\
\hline \multirow{2}{*}{ First-mover effort } & 0.250 & 0.164 & $0.434^{* *}$ & $0.538^{* *}$ \\
& $(0.215)$ & $(0.149)$ & $(0.214)$ & $(0.248)$ \\
High first & $15.183^{* * *}$ & 5.235 & $18.731^{* * *}$ & 4.370 \\
& $(0.180)$ & $(9.515)$ & $(4.598)$ & $(9.097)$ \\
High first $\times$ First-mover & -0.432 & -0.414 & $-1.926^{* * *}$ & -0.802 \\
effort & $(1.349)$ & $(0.785)$ & $(0.427)$ & $(0.774)$ \\
Constant & 7.384 & $7.015 * * *$ & $6.339 * * *$ & $6.745^{* * *}$ \\
& $(1.435)$ & $(0.930)$ & $(1.387)$ & $(1.717)$ \\
\hline $\mathrm{R}^{2}$ & .040 & .025 & .328 & .077 \\
\hline
\end{tabular}

The table displays coefficients with robust standard errors in parentheses

$*$ significant at $\mathrm{p}<.1 ; * *$ significant at $\mathrm{p}<.05 ; * * *$ significant at $\mathrm{p}<.01$ 